\title{
On the electrolytic behaviour of mica at high temperatures
}

\section{W.H. Schultze}

To cite this article: W.H. Schultze (1889) On the electrolytic behaviour of mica at high temperatures, Philosophical Magazine Series 5, 27:167, 368-368, DOI: 10.1080/14786448908628370

To link to this article: http://dx.doi.org/10.1080/14786448908628370

曲 Published online: 29 Apr 2009.

Submit your article to this journal $[\pi$

Џll Article views: 2

Q View related articles $₫$ 
and still more difficult to maintain, the sheath, which at the smallest agitation is transformed into crepitating bubbles.

This resonant form of electrolysis is accompanied by a superficial disaggregation of the negative electrode; the liquid soon becomes charged with a very heavy black powder, which is essentially composed of a hydride of platinum; this decomposes in a vacuum above $400^{\circ}$ and corresponds to the formula $\mathrm{Pt}_{2} \mathbf{H}$.

We have hitherto only been concerned with the phenomena met with at the negative pole. A sheath may also be observed on the positive pole. For this purpose it is sufficient to invert the conditions of the experiment, to attach to the negative pole the wire of 4.5 millim., always deeply immersed in the same water acidulated to $\frac{1}{10}$, and to gradually immerse the positive electrode, which is a wire of 1.6 millim. diameter. There is considerable difficulty in obtaining the sheath, which does not form sharply with less than 50 volts, but which in return is remarkably persistent; it is moreover much less luminous.

If the sheath is first of all formed on the stout wire, which is immersed to a depth of 2 to 3 centim., in proportion as the stout wire is immersed the sheath elongates to the point at which it disappears suddenly; but at the same time the strength of the current increases, and the other electrode may become so much heated as in turn to be covered with a luminous sheath, or with crepitating bubbles.

Similar phenomena, though far less intense, are met with in water acidulated with phosphoric acid. The normal decomposition is disturbed with greater difticulty, as has already been pointed out by M. Mascart t.-Comptes Rendus, Feb. 11, 1889.

\section{ON THE ELECTROLYTIC BEHAVIOUR OF MICA AT HIGH TEMPERATURES. BY W. H. SCHULTZE.}

The results of this investigation are as follows :-

Mica split parallel to the planes of cleavage shares with glass the property of becoming a better conductor for the current as the temperature rises. After reaching a maximum, its conductivity diminishes; and at a certain high temperature it becomes infinitely small.

Comparing mica and glass, it is seen that even at a high temperature the former is the better insulator.-Wiedemann's Annalen, vol. xxxvi. p. 635,1889 .

* Berthelot, Annales de Chimie et de Physique, 5th series, vol. xxx. p. 530 (1883).

† Journal de Physique, series 2, vol. i. p. 111 (1882). 